\title{
EFFECTS OF INTERPROFESSIONAL COLLABORATION PROGRAM IN COMMUNITY ON THE PERCEPTION OF PHARMACY AND MEDICAL STUDENTS
}

\author{
Christianus Heru Setiawan*), Rita Suhadi, Phebe Hendra, Fenty, Dita Maria Virginia, \\ Gregorius Bhaskara Wikanendra
}

\author{
Faculty of Pharmacy, Sanata Dharma University, Paingan, Maguwoharjo, Depok, Sleman, \\ Yogyakarta, 55282, Indonesia
}

Received November 29, 2019; Accepted April 18, 2020

\begin{abstract}
Cardiovascular disease is the highest cause of mortality in Indonesia. One of the factors that causes the disease is low level of health awareness, including healthy lifestyle and health control. Improving public health awareness can be done by providing health education in collaboration with interprofessional health services. A collaboration involving students from various healthrelated disciplines aims to build good collaboration in the future after the corresponding students become health workers. This study is quasi-experimental. Students from health-related disciplines, especially pharmacy and medical students, were authorized to work directly in health screening and to provide education to the community. Student's perceptions on the Interprofessional Collaboration (IPC) program were explored through Student Perceptions of Physician-Pharmacist Interprofessional Clinical Education (SPICE) questionnaire, which were given before and after the community project. Among 87 SPICE questionnaires, 78 questionnaires filled in completely were collected from pharmacy and medical students. The results of the questionnaire showed good perceptions before and after activities in the community with mean scores of $4.46(0.35)$ and 4.5 (0.37) respectively. Wilcoxon test results found no significant difference on the total SPICE scores before and after the activity ( $>>$.05). One item from the SPICE questionnaire, which was the seventh item related to understanding the role of other professionals in the interdisciplinary team, had a significant increase $(\mathrm{P}<.05)$.
\end{abstract}

Keywords: Interprofessional Collaboration (IPC); Interprofessional Education (IPE); medical student; pharmacy student.

\section{INTRODUCTION}

Cardiovascular disease is still the highest threat of mortality in Indonesia. The dominating cause suffered by Indonesian population is hypertension. The prevalence of hypertension among subjects in Sleman Regency was almost 50\% and had a very low adherence to therapy. Adherence to therapy was found in only $13.5 \%$ of hypertension subjects (Suhadi et al., 2015). The prevalence of hyperglycemia was $9.9 \%$, dyslipidemia was $17.6 \%$, and overweight and obesity was $56.3 \%$, which indicates low level of health and public awareness about health (Suhadi et al.,
2017, 2015). In addition, cardiovascular risk factors such as smoking, lack of physical activity, hypertension, hyperlipidemia, and diabetes induce the development of atherosclerosis. Exposure to these risk factors accelerates atherosclerosis and the process of complex plaque formation, narrowing of blood vessels, and blockage of blood flow in vital organs covering the kidneys, heart and brain (Douglas et al., 2014).

Literatures show that other obstacles identified in blood pressure management are high drug prices, forgetting to take medication, high trust in alternative medicine, lack of 
understanding of the treatment received, and poor doctor-patient relationships (Perera et al., 2019). Another dominant factor that adversely affects blood pressure is smoking (Mitra et al., 2019). Result from cross-sectional survey undertaken with diabetic patients in India, show slow health awareness about diabetes, from 207 diabetic patients only 37 (18\%) were aware of having diabetes (Tripathy et al., 2017). This fact shows great potential for developing cardiovascular occurrences in this population. Besides, hypertension and diabetes are closely related to body composition, and overweight individuals tend to suffer from this disease. People living in rural communities tend to be more easily overweight compared to those living in urban communities. So, there is a need for counseling, examinations, and interventions that target this population (Patterson et al., 2002).

Interprofessional collaboration is considered essential for the provision of safe, effective, and efficient medical services. This collaboration serves as a response to medication errors that cause serious adverse effects and potentially cause a fatal risk of disease. Medical error ranks fifth in the top ten causes of death in the United States according to the Joint Commission on Accreditation of
Healthcare Organizations. The root of the problem is poor collaboration between health workers that causes treatment delays and fatal errors in surgery (Hakiman et al., 2016).

Interprofessional Education (IPE) is an educational activity between two or more students from health-related disciplines that aims to improve the understanding on the competencies of each profession that ultimately creates collaboration or ready to work together. IPE can occur in communitybased experience programs. Community-based experience shows how Inter-professional Collaborations (IPC) provides services to patients and how the environment and availability of resources have impact on health status (Bridges et al., 2011). Students majoring in health-related disciplines, as prospective professionals, can be trained to provide education independently in collaboration with other health professional students. This collaboration can create a collaborative environment that is expected to be applied until they become health professionals (Figure 1). Because of the reasons, it is necessary to examine student perceptions in working together to educate the public to control the risk of cardiovascular disease.

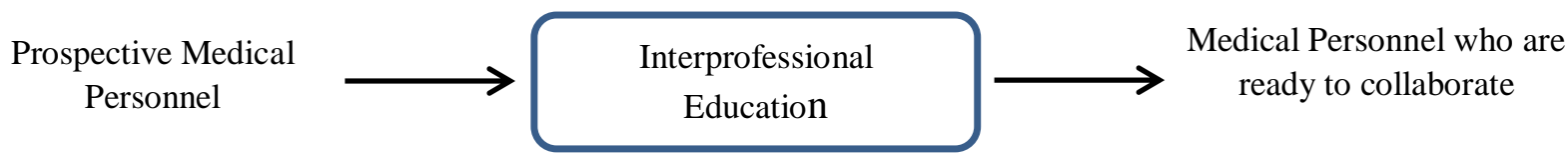

Figure 1. A Framework for Interprofessional Education 


\section{METHODS}

This research is quasi-experimental. Student perceptions about teamwork, roles, and responsibilities through the Student Perceptions of Physician-Pharmacist Interprofessional Clinical Education (SPICE) questionnaire were investigated. The ethical clearance of this study, No. 1077/C.16/FK/2019, was issued by the Ethics Committee from Duta Wacana Christian University. The program was carried by the Faculty of Pharmacy Universitas Sanata Dharma and the Medical Faculty of Universitas Kristen Duta Wacana by involving 48 pharmacy students in semester 7 from Universitas Sanata Dharma and 39 medical students in semester 7 from Universitas Kristen Duta Wacana. The participants were divided into four groups. Each group performed educating process with the following details. Group 1 provided education on the topic of hypertension in the first month, group 2 provided education on the topic of diabetes mellitus in the second month, group 3 provided education on the topic of dyslipidemia in the third month, and group 4 provided education on the topic of obesity in the fourth month. Students' individual tasks were divided by their specialties with medical student focused on physical examination and pharmacy students focused on education of healthy life and adherence to medication. In addition, the students had to monitor public health including blood pressure checking, body mass index (BMI), blood sugar, blood cholesterol, uric acid, and other vital signs every month. The monthly activities were supervised by teaching staff from the Faculty of Pharmacy and Faculty of Medicine.

Before educating and examining the residents, students had undergone training to conduct counseling and peripheral blood examinations provided by the teaching staff of the Faculty of Pharmacy, Universitas Sanata Dharma and Faculty of Medicine, Universitas Kristen Duta Wacana. Materials provided during the training included how to deliver educational material to the community, healthy lifestyle, goals of pharmacological and non-pharmacological therapy, how to take blood pressure, BMI, and blood sampling (blood sugar, blood cholesterol, uric acid). The education module was created collaboratively by lecturers from both universities. The created module contained materials about cardiovascular risk, hypertension, diabetes, dyslipidemia, and adherence to the therapy. The Student Perceptions of PhysicianPharmacist Interprofessional Clinical Education (SPICE) questionnaire was given before the training session and after the students conducted counseling and health examination on residents. The questionnaire consisted of 10 questions regarding teamwork, roles and responsibilities, and patient outcomes. Each statement was given different scales from 5 (strongly agree), 4 (agree), 3 (neutral), 2 (disagree), to 1 (strongly disagree). The questionnaire results were processed with statistical assistance from the Wilcoxon test because the data were not normally distributed to discover differences on students' perceptions on interprofessional collaboration before training and after the counseling and health examination on residents.

\section{RESULTS AND DISCUSSION}

Table 1 shows that the average number of students from pharmacy was slightly higher. A total of 87 questionnaires were collected from students with the exclusion of 9 questionnaires because they were not filled out completely (Figure 2).

Table 1. The number of students in each counseling and examination session $(n=87)$

\begin{tabular}{cccc}
\hline Group & Pharmacy Student & Medical Student & Total \\
\hline Group 1 (first month) & 12 & 10 & 22 \\
\hline Group 2 (second month) & 12 & 10 & 22 \\
\hline Group 3 (third month) & 12 & 9 & 21 \\
\hline Group 4 (fourth month) & 12 & 10 & 22 \\
\hline Total & 48 & 39 & 87 \\
\hline
\end{tabular}




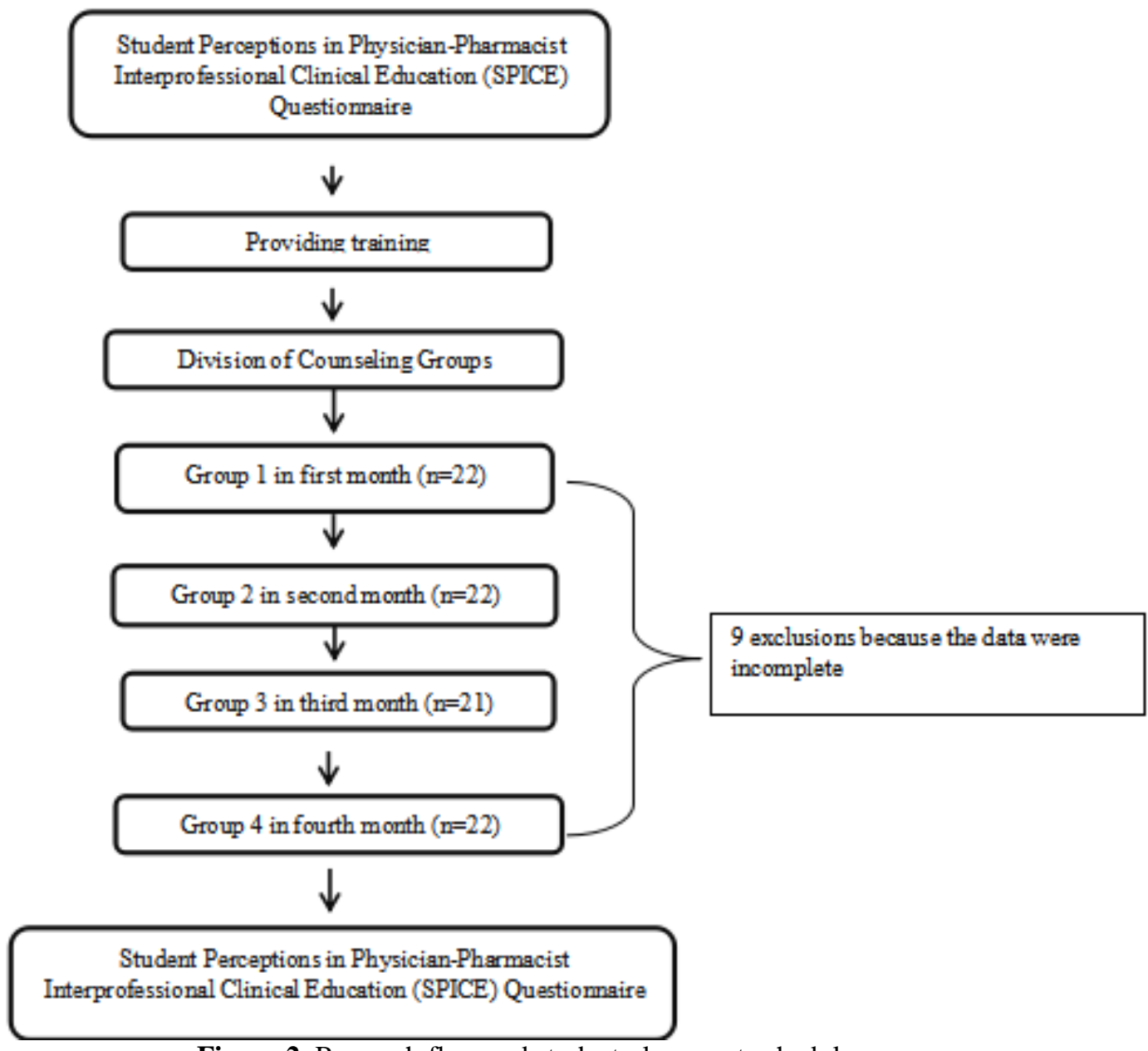

Figure 2. Research flow and student placement schedule

Table 2 shows that mean total scores of SPICE in pre-activity were already superior and mean scores in post-activity remained superior, i.e. 4.46 out of 5 and 4.5 out of 5 respectively. The results of statistical tests with Wilcoxon showed no significant difference between total pre and post SPICE scores ( $\mathrm{P}>$.05). SPICE scores on interprofessional teamwork and team-based practice (statements 1, 5, 6, and 8-10) showed no significant difference between pre- and post-activity $(\mathrm{P}>$.05). SPICE scores regarding roles/responsibilities in collaborative practice (statements 2 and 7) showed no significant difference between pre- and post-activity scores $(\mathrm{P}>$.05). SPICE scores regarding patient outcomes from collaborative practice (statements 3 and 4) showed no significant difference between pre-education and posteducation scores $(\mathrm{P}>$.05). The results imply that the students have already had a high perception on interprofessional collaboration as those students had been exposed to interprofessional education materials from their lecturer while in college. A study that targeted 837 fourth-year students from numerous disciplines (i.e., nursing, medicine, dentistry, pharmacy, social welfare, food and nutrition, environmental engineering, medical engineering, public health, clinical pathology, physical therapy, occupational therapy, radiology, and dental hygiene) suggests that it is important for students from various majors to have an open mind, accept different views, recognize their own limits, respect other majors, and cooperate with each other to enhance their learning experience (Kim et al., 2019). It shows the congruence in which interprofessional education must be carried out as part of formal learning to enhance their competence in collaborating with individuals from other health-related professions. 
Table 2. SPICE score according to descriptors $(n=78)$

\begin{tabular}{|c|c|c|c|}
\hline Factor & $\begin{array}{c}\text { Pre } \\
\text { Median (Min-max) } \\
\text { Mean (SD) }\end{array}$ & $\begin{array}{c}\text { Post } \\
\text { Median (Min-max) } \\
\text { Mean (SD) } \\
\end{array}$ & P-value* \\
\hline \multirow{2}{*}{$\begin{array}{l}\text { Working with another discipline of students } \\
\text { enhances my education (Item 1) }\end{array}$} & $5(4-5)$ & $5(3-5)$ & \multirow{2}{*}{.57} \\
\hline & $4.59(0.49)$ & $4.55(0.52)$ & \\
\hline \multirow{2}{*}{$\begin{array}{l}\text { My role within the interdisciplinary team is clearly } \\
\text { defined (Item 2) }\end{array}$} & $4(3-5)$ & $4(2-5)$ & \multirow{2}{*}{.69} \\
\hline & $4.13(0.63)$ & $4.17(0.65)$ & \\
\hline \multirow{2}{*}{$\begin{array}{l}\text { Health outcomes are improved when patients are } \\
\text { treated by a team of professionals from different } \\
\text { disciplines (Item 3) }\end{array}$} & $5(3-5)$ & $5(3-5)$ & \multirow{2}{*}{.73} \\
\hline & $4.6(0.51)$ & $4.58(0.52)$ & \\
\hline \multirow{2}{*}{$\begin{array}{l}\text { Patient satisfaction is improved when patients are } \\
\text { treated by a team of professionals from different } \\
\text { disciplines (Item 4) }\end{array}$} & $4(3-5)$ & $5(3-5)$ & \multirow{2}{*}{.50} \\
\hline & $4.4(0.56)$ & $4.45(0.65)$ & \\
\hline \multirow{2}{*}{$\begin{array}{l}\text { Participating in educational experiences with another } \\
\text { discipline of students enhances my future ability to } \\
\text { work on an interdisciplinary team (Item 5) }\end{array}$} & $5(4-5)$ & $5(3-5)$ & \multirow{2}{*}{.28} \\
\hline & $4.63(0.48)$ & $4.55(0.55)$ & \\
\hline \multirow{2}{*}{$\begin{array}{l}\text { All health professions students should be educated to } \\
\text { establish collaborative relationships with members } \\
\text { from other disciplines (Item 6) }\end{array}$} & $5(3-5)$ & $5(4-5)$ & \multirow{2}{*}{.85} \\
\hline & $4.65(0.5)$ & $4.64(0.48)$ & \\
\hline \multirow{2}{*}{$\begin{array}{l}\text { I understand the roles of other professionals within } \\
\text { the interdisciplinary team (Item 7) }\end{array}$} & $4(3-5)$ & $4(3-5)$ & \multirow{2}{*}{.01} \\
\hline & $4(0.52)$ & $4.23(0.6)$ & \\
\hline \multirow{2}{*}{$\begin{array}{l}\text { Clinical rotations are the ideal place within their } \\
\text { respective curricula for medical and pharmacy } \\
\text { students to interact (Item } 8 \text { ) }\end{array}$} & $4(3-5)$ & $5(3-5)$ & \multirow{2}{*}{.53} \\
\hline & $4.41(0.59)$ & $4.46(0.59)$ & \\
\hline \multirow{2}{*}{$\begin{array}{l}\text { Physicians and pharmacists should collaborate in } \\
\text { teams (Item 9) }\end{array}$} & $5(4-5)$ & $5(4-5)$ & \multirow{2}{*}{.18} \\
\hline & $4.69(0.46)$ & $4.77(0.42)$ & \\
\hline \multirow{2}{*}{$\begin{array}{l}\text { During their education, medical and pharmacy } \\
\text { students should be involved in teamwork in order to } \\
\text { understand their respective roles (Item 10) }\end{array}$} & $5(3-5)$ & $5(3-5)$ & \multirow{2}{*}{.20} \\
\hline & $4.58(0.54)$ & $4.65(0.5)$ & \\
\hline \multirow{2}{*}{$\begin{array}{l}\text { Interprofessional Teamwork and Team-Based } \\
\text { Practice (Items } 1,5,6, \& 8-10 \text { ) }\end{array}$} & $4.67(3.83-5)$ & $4.67(3.67-5)$ & \multirow{2}{*}{.99} \\
\hline & $4.59(0.37)$ & $4.6(0.38)$ & \\
\hline \multirow{2}{*}{$\begin{array}{l}\text { Roles/Responsibilities for Collaborative Practice } \\
\text { (Items } 2 \& 7 \text { ) }\end{array}$} & $4(3-5)$ & $4(2.5-5)$ & \multirow{2}{*}{.07} \\
\hline & $4.07(0.47)$ & $4.19(0.51)$ & \\
\hline \multirow{2}{*}{$\begin{array}{l}\text { Patient Outcomes from Collaborative Practice (Items } \\
3 \& 4 \text { ) }\end{array}$} & $4.5(3-5)$ & $4.5(3.5-5)$ & \multirow{2}{*}{.70} \\
\hline & $4.5(0.45)$ & $4.51(0.54)$ & \\
\hline \multirow{2}{*}{ Total } & $4.6(3.7-5)$ & $4.6(3.7-5)$ & \multirow{2}{*}{.50} \\
\hline & $4.46(0.35)$ & $4.5(0.37)$ & \\
\hline
\end{tabular}

*Wilcoxon test 
Statement 7 from SPICE questionnaire regarding understanding the roles of other professionals within the interdisciplinary team had a significant increase between before and after activity $(\mathrm{P}<.05)$. This result is in line with research conducted by Riskiyana (2018) revealing that Inter-professional Collaborations (IPC) learning can improve student understanding and performance on inter-professional collaboration. This collaboration improves the quality of service by increasing the behavior of the health service team in collaborating between professionals (Riskiyana et al., 2018). A study that compares group of internal medicine residents, nurse practitioners trainees, psychology trainees, and pharmacy students who participated in a Centers of Excellence in Primary Care Education (CoEPCE) initiative and those who did not participate in CoEPCE initiative. These two different groups created one working group each to give educational activities to patients. Results showed that the CoEPCE initiative was associated with modest improvements in quality of care and gave improvements in patient outcomes (Edwards et al., 2019).

The obstacle in conducting collaborative practice is difficulty in uniting the opinions of each student. A study shows that some health care professionals still have an ego where they feel that their opinions are the most correct (Rachma Sari et al., 2018). Health professionals, such as nurses and midwives, report that they often find obstacles in participating in decision making, especially during ward rounds. They only serve to convey information and answer doctors' questions about the patient's condition and are not involved in providing input for decision making (Lestari et al., 2016). Another obstacle that can hamper collaborative practice is that there are many areas of overlapping responsibility among health workers (Setiadi et al., 2017). This can be prevented by learning IPC which can increase understanding on the role of other health workers in serving the community. Other important things are interventions in IPC practice namely education, daily communication, collaborative team visits, case presentations, and treatment reconciliation to improve communication, team care, outcomes for subgroups of high-risk patients, and productivity of health care providers (Nagelkerk et al., 2018).

The interprofessional collaboration learning activity showed little change in interprofessional perception according to SPICE instruments because participants had a high perception at the beginning of the study with a slight improvement at the end of the study. The results indicate that the students had been exposed to interprofessional education from their universities. Interprofessional collaboration learning is recommended to enter formal curriculum for students of health-related majors to improve their competence and to prepare the students for collaborating with other health workers to deliver excellent health services.

\section{CONCLUSION}

Inter-professional Collaborations (IPC) learning provides new experiences for students. Health education can be provided collaboratively by health professionals who need cooperation from various health professions. Good collaboration requires trust from professional colleagues, high competence from each profession, effective communication, and knowledge of competencies among other health professions. Suggestions for this research need to be measured from the perspective of community members who got education and examination regarding IPC activities that have been carried out. 


\section{ACKNOWLEDGEMENT}

The authors would like to thank research and community service institution or Lembaga Penelitian dan Pengabdian Kepada Masyarakat (LPPM), Universitas Sanata Dharma for the research grant through Hibah Penelitian Dosen scheme year 2019, United Board for the project grant, and participants who have been willing to take part in this research.

\section{REFERENCES}

Bridges, D.R., Davidson, R.A., Odegard, P.S., Maki, I.V., Tomkowiak, J., 2011. Interprofessional collaboration: Three best practice models of interprofessional education. Medical Education Online, 16(1), 1-10.

Douglas, G., Channon, K.M., 2014. The pathogenesis of atherosclerosis. Medicine, 1-5.

Edwards, S.T., Hooker, E.R., Brienza, R., O'Brien, B., Kim, H., Gilman, S., Harada, N., Gelberg, L., Shull, S., Niederhausen, M., King, S., Hulen, E., Singh, M.K., Tuepker, A., 2019. Association of a Multisite Interprofessional Education Initiative With Quality of Primary Care. JAMA Network Open, 2(11), e1915943e1915943.

Hakiman, A.P., Dewi, S.P., Sayusman, C., Wahyudi, K., 2016. Persepsi Mahasiswa Profesi Kesehatan Universitas Padjadjaran Terhadap Interprofessionalism Education. Jurnal Sistem Kesehatan, 1(4), 206-213.

Kim, J., Lee, H., Kim, I.S., Lee, T.W., Kim, G.S., Cho, E., Lee, K.H. 2019. Interprofessional global health competencies of South Korean health professional students: educational needs and strategies. BMC Medical Education, 19(1), 429.

Lestari, E., Stalmeijer, R.E., Widyandana, D., Scherpbier, A., 2016. Understanding students' readiness for interprofessional learning in an Asian context: A mixedmethods study. BMC Medical Education, $16,179$.
Mitra, M., Wulandari, W. 2019. Factors affecting uncontrolled blood pressure among elderly hypertensive patients in Pekanbaru City, Indonesia. Open Access Macedonian Journal of Medical Sciences, 7(7), 1209-1213.

Nagelkerk, J., Thompson, M.E., Bouthillier, M., Tompkins, A., Baer, L.J., Trytko, J., Booth, A., Stevens, A., Groeneveld, K., 2018. Improving outcomes in adults with diabetes through an interprofessional collaborative practice program. Journal of Interprofessional Care, 32(1), 4-13.

Patterson, P.D., Moore, C.G., Probst, J.C., Samuels, M.E. 2002. Hypertension, Diabetes, Cholesterol, Weight, and Weight Control Behaviors Among NonMetro Minority Adults. Columbia.

Perera, M., de Silva, C.K., Tavajoh, S., Kasturiratne, A., Luke, N.V., Ediriweera, D.S., Ranasinha, C.D., Legido-Quigley, H., de Silva, H.A., Jafar, T.H. 2019. Patient perspectives on hypertension management in health system of Sri Lanka: a qualitative study. BMJ Open, 9(10), e031773.

Rachma Sari, V., Hariyati, R.T.S., Syuhaimie Hamid, A.Y., 2018. The association between stereotyping and interprofessional collaborative practice. Enfermeria Clinica, 28, 134-138.

Riskiyana, R., Claramita, M., Rahayu, G.R., 2018. Objectively measured interprofessional education outcome and factors that enhance program effectiveness: A systematic review. Nurse Education Today, 66(July), 73-78.

Setiadi, A.P., Wibowo, Y., Irawati, S., Setiawan, E., Presley, B., Gudka, S., Wardhani, A.S., 2017. Indonesian pharmacists' and pharmacy students' attitudes towards collaboration with physicians. Pharmacy Practice, 15(4), 1052.

Suhadi, R., Linawati, Y., Virginia, D.M., Setiawan, C.H. 2015. Early Implementation of Universal Health Coverage Among Hypertension Subjects in Sleman District of Yogyakarta. Acta medica Indonesiana, 47(4), 311-319. 
Suhadi, R., Linawati, Y., Wulandari, E.T., Viriginia, D.M., Setiawan, C.H. 2017. The metabolic disorders and cardiovascular risk among lower socioeconomic subjects in YogyakartaIndonesia. Asian Journal of Pharmaceutical and Clinical Research, 10(3), 367-372.
Tripathy, J.P., Thakur, J.S., Jeet, G., Chawla, S., Jain, S., Pal, A., Prasad, R., Saran, R. 2017. Prevalence and risk factors of diabetes in a large community-based study in North India: results from a STEPS survey in Punjab, India. Diabetology \& metabolic syndrome, 9, 8 . 